\title{
Multidrug Resistance in Klebsiella pneumoniae MGH78578 and Cloning of Genes Responsible for the Resistance
}

\author{
Wakano Ogawa, ${ }^{a}$ Dai-Wei Li, ${ }^{a}$ Ping Yu, ${ }^{a}$ Anowara Begum, ${ }^{a}$ Tohru Mizushima, ${ }^{b}$ \\ Teruo KurodA, ${ }^{a}$ and Tomofusa TsuchiYA ${ }^{*, a}$ \\ ${ }^{a}$ Department of Molecular Microbiology, Graduate School of Medicine, Dentistry and Pharmaceutical Sciences, Okayama \\ University; Tsushima-Naka, Okayama 700-8530, Japan: and ${ }^{b}$ Graduate School of Medical and Pharmaceutical Sciences, \\ Kumamoto University; Kumamoto 862-0973, Japan. Received March 22, 2005; accepted May 9, 2005
}

\begin{abstract}
Klebsiella pneumoniae MGH78578, a clinical isolate, showed high level of resistance to many antimicrobial agents. We cloned genes responsible for drug resistance from chromosomal DNA of $K$. pneumoniae MGH78578 by shotgun method using Escherichia coli KAM32, a drug hypersensitive strain, as host. We obtained 43 hybrid plasmids that made host cells resistant to several antimicrobial agents. We classified them into 17 groups based on growth properties in the presence of each one of 9 antimicrobial agents and on restriction patterns of each hybrid plasmid. Analysis of the cloned genes must be very useful for investigation of major parts of multidrug resistance systems including multidrug efflux pumps in $K$. pneumoniae MGH78578 in which genome sequence is available.
\end{abstract}

Key words multidrug resistance; multidrug efflux pump; gene cloning; Klebsiella pneumoniae

According to statistics of World Health Organization in 2004, 3.9 millions of people died of pneumoniae in a year (http://www.who.int/whr/2004/annex/topic/en/annex_2_en. pdf). This number represents worst 1 among causes of human death due to microbial infections. In Japan, pneumoniae is the fourth cause of human death following cancer, heart diseases and brain diseases (http://www1.mhlw.go.jp/ english/wp_5/vol1/p1c3s1.html). Ishida and coworkers reported that Klebsiella pneumoniae is one of the major bacteria causing pneumoniae. ${ }^{1)} \mathrm{K}$. pneumoniae often causes respiratory infections and urinary tract infections. ${ }^{1-3)}$ It is important to treat patients infected with $K$. pneumoniae by using antimicrobial agents at early stage of infection. ${ }^{4)}$ Recently, however, it has been reported that multidrug resistant $K$. pneumoniae has often been isolated in hospitals, and this has been becoming big clinical problems. ${ }^{5-8)}$ There are five major mechanisms of drug resistance in bacteria, 1) inactivation of drugs due to degradation or modification by enzyme, 2) alteration in target of drugs, 3) emergence of bypass which is not inhibited by drugs, 4) reduced membrane permeability for drugs, and 5) active efflux of drugs from cells by drug efflux pumps, especially by multidrug efflux pumps. Multidrug efflux pumps are responsible for multidrug resistance in many bacteria. ${ }^{9)}$ Extended-spectrum $\beta$-lactamase (ESBL) has been reported as a cause of resistance to $\beta$-lactams in clinical isolates of $K$. pneumoniae. ${ }^{7,8)}$ Also it has been reported that strains of $K$. pneumoniae that produced ESBL were also resistant to other types antimicrobial agents. ${ }^{8,10}$ Although DNA gyrase and topoisomerase IV are targets of fluoroquinolones, fluoroquinolone-resistant strains of $K$. pneumoniae that did not show any mutation in genes for these targets have been reported. ${ }^{11-13)}$ These results suggest that multidrug efflux pumps are involved in the resistance against multiple antimicrobial agents in clinical isolates of $K$. pneumoniae.

Five families of multidrug efflux pumps are known in bacteria, ${ }^{9)}$ 1) resistance nodulation cell division (RND) family, 2) major facilitator (MF) family, 3) small multidrug resistance (SMR) family, 4) multidrug and toxic compound extru- sion (MATE) family, and ATP binding cassette (ABC) family. It has been suggested that AcrAB-like RND-type multidrug efflux pump might be involved in quinolone resistance in K. pneumoniae (A. Domenech-Sanchez, S. Alberti, L. Martinez-Martinez, A. Pascual, I. Garcia, and V. J. Benedi, Abstr. 41st Intersci. Conf. Antimicrob. Agents Chemother., abstr. C1-2018, p. 104, 2001). In addition, it has been reported that expression of acrA-like gene was elevated in some clinically isolated strains of $K$. pneumoniae. ${ }^{14)}$ It is important to understand whole features of multidrug efflux pumps in K. pneumoniae and properties of each pump to get insight into multidrug resistance in $K$. pneumoniae, and to control its multidrug resistance and to treat patients infected with multidrug-resistant $K$. pneumoniae successfully. Here we aimed to clone as many genes for multidrug resistance, especially for multidrug efflux pumps, as possible in this microorganism. We report patterns of drug resistance in a multidrug resistant strain of $K$. pneumoniae and functional cloning of many genes responsible for the multidrug resistance.

\section{MATERIALS AND METHODS}

Bacterial Strains and Media $K$. pneumoniae MGH78578 was kindly provided by Dr. Michael McClelland of the Sidney Kimmel Cancer Center in San Diego, CA, U.S.A. K. pneumoniae ATCC10031 was purchased from American Type Culture Collection. Escherichia coli KAM32 lacks major multidrug efflux pumps, AcrAB and YdhE, and a restriction system. ${ }^{15)}$ This strain is hypersensitive to many kinds of antimicrobial agents, and is very useful as host for cloning of genes for drug resistance systems. Cells were grown in $\mathrm{L}$ medium ( $1 \%$ polypeptone, $0.5 \%$ yeast extract and $0.5 \% \mathrm{NaCl}, \mathrm{pH} 7.0$ ), except for measurement of minimum inhibitory concentration (MIC), at $37^{\circ} \mathrm{C}$ under aerobic conditions. Growth of cells was monitored turbidmetrically at $650 \mathrm{~nm}$.

Determination of the MICs The MICs of various antimicrobial agents were determined in Mueller-Hinton broth 
(Difco, Sparks, U.S.A.) by the two-fold dilution method. ${ }^{16)}$ Cells in the test medium $\left(10^{5}\right.$ cells $\left./ \mathrm{ml}\right)$ were incubated at $37^{\circ} \mathrm{C}$ for $24 \mathrm{~h}$, and the growth was subsequently measured.

Ethidium Transport Assay $K$. pneumoniae cells were grown in the L medium. The cells were harvested at the exponential phase of growth, and washed with modified Tanaka medium $^{17)}\left(\mathrm{pH}^{7} .0\right)$, in which sodium salts were replaced with potassium salts, containing $2 \mathrm{mM} \mathrm{MgSO}_{4}$ twice. The washed cells were suspended with the modified Tanaka medium containing $2 \mathrm{~mm} \mathrm{MgSO}_{4}$. The assays were performed at $37^{\circ} \mathrm{C}$. Ethidium bromide was added to cell suspension of each $K$. pneumoniae cells at a final concentration of $20 \mu \mathrm{M}$. Accumulation of ethidium was monitored continuously by measuring the fluorescence of ethidium in cells at the excitation and emission wavelengths of $500 \mathrm{~nm}$ and $580 \mathrm{~nm}$, respectively. After $5 \mathrm{~min}$, carbonylcyanide $m$ chlorophenylhydrazone (CCCP) was added to the cell suspension at a final concentration of $100 \mu \mathrm{M}$ to dissipate an electrochemical potential of $\mathrm{H}^{+}$across the membranes.

Gene Cloning Chromosomal DNA was prepared from $K$. pneumoniae MGH78578 by the method of Berns and Thomas. ${ }^{18)}$ The DNA was partially digested with restriction enzyme Sau3AI, and the fragments ranging in size from 4 to $10 \mathrm{kbp}$ were separated by sucrose density gradient centrifugation. Plasmid pBluescript II SK(-), pMW119 (Nippon Gene Co.) and pSTV28 (Takara Co.) were digested with restriction enzyme BamHI, dephosphorylated with bacterial alkaline phosphatase, and ligated with the 4 to $10 \mathrm{kbp}$ chromosomal DNA fragments by using a ligation kit (Nippon Gene, Ligation convenient kit).

Competent cells of $E$. coli KAM32 were transformed with the recombinant plasmids and were spread on the $\mathrm{L}$ agar plates (the L medium plus $1.5 \%$ agar) containing each antimicrobial agent and $40 \mu \mathrm{g} / \mathrm{ml}$ of ampicillin $(20 \mu \mathrm{g} / \mathrm{ml}$ of chloramphenicol instead of ampicillin was used for pSTV28 vector). The plates were incubated at $37^{\circ} \mathrm{C}$ for 24 to $36 \mathrm{~h}$, and colonies appeared on the plates were picked up. The antimicrobial agents used for this gene cloning and their concentrations were as follows: ethidium bromide at $10 \mu \mathrm{g} / \mathrm{ml}$, norfloxacin at $0.05 \mu \mathrm{g} / \mathrm{ml}, 4^{\prime}, 6$-diamidino-2-phenylindole dihydrochloride (DAPI) at $0.5 \mu \mathrm{g} / \mathrm{ml}$, erythromycin at $4 \mu \mathrm{g} / \mathrm{ml}$, tetraphenylphosphonium chloride (TPPCl) at $32 \mu \mathrm{g} / \mathrm{ml}$, and kanamycin at $4 \mu \mathrm{g} / \mathrm{ml}$.

\section{RESULTS AND DISCUSSION}

MICs of Antimicrobial Agents $K$. pneumoniae MGH78578 is a clinical isolate. K. pneumoniae ATCC10031 is from American Type Culture Collection. We measured MICs of 15 antimicrobial agents in the two strains. As shown in Table 1, the strain MGH78578 showed much higher MICs of most of the antimicrobial agents including $\beta$-lactams, norfloxacin, erythromycin, kanamycin, tetracycline, chloramphenicol and others, except imipenem, than the strain ATCC10031. The MIC values observed in $K$. pneumoniae MGH78578 are much higher than those in wild type cells of E. coli (data not shown). Thus, it is clear that the MGH78578 is highly resistant to many antimicrobial agents, namely the MGH78578 is a multidrug resistant strain.

Efflux Activity for Ethidium Among the drug resistance systems in bacterial cells, multidrug efflux pump can
Table 1. Drug Susceptibility in Klebsiella pneumoniae

\begin{tabular}{|c|c|c|}
\hline \multirow{3}{*}{ Drugs } & \multicolumn{2}{|c|}{$\mathrm{MIC}(\mu \mathrm{g} / \mathrm{ml})$} \\
\hline & \multicolumn{2}{|c|}{ Strains } \\
\hline & MGH78578 & ATCC10031 \\
\hline Ampicillin & $>1024$ & 64 \\
\hline Cefotaxime & 16 & 0.008 \\
\hline Oxacillin & $>2048$ & 16 \\
\hline Imipenem & 0.5 & 0.5 \\
\hline Norfloxacin & 8 & 0.125 \\
\hline Erythromycin & 256 & 16 \\
\hline Kanamycin & 1024 & 2 \\
\hline Tetracycline & 512 & 4 \\
\hline Chloramphenicol & 1024 & 2 \\
\hline Acriflavine & 256 & 16 \\
\hline Benzalkonium chloride & 32 & 16 \\
\hline Ethidium bromide & 1024 & 64 \\
\hline Rhodamine 6G & $>1024$ & 64 \\
\hline $\operatorname{SDS}^{a)}$ & 2048 & 256 \\
\hline TPPCl & $>1024$ & 128 \\
\hline
\end{tabular}

a) SDS, sodium dodecyl sulfate.

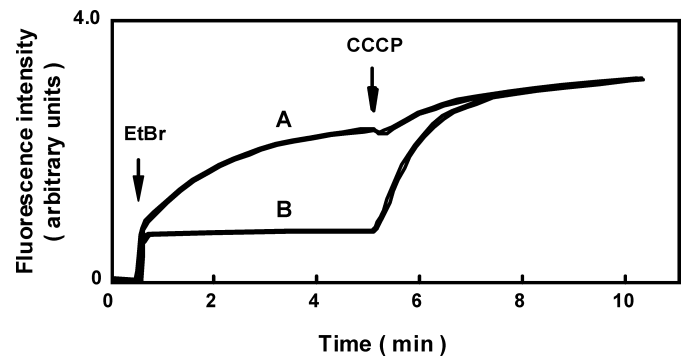

Fig. 1. Ethidium Efflux Activities in K. pneumoniae ATCC10031 (A) and MGH78578 (B)

Levels of intracellular ethidium were monitored by measuring fluorescence intensity. At time point indicated by the first downward arrow, ethidium bromide $(\mathrm{EtBr}$, final $20 \mu \mathrm{M})$ was added, and at time point indicated by the second downward arrow, CCCP (final $100 \mu \mathrm{M}$ ) was added to de-energize the cells.

extrude multiple drugs, and could contribute to the multidrug resistance. Ethidium bromide is often used as a substrate for multidrug efflux pumps. Since we observed high level resistance to ethidium bromide in the strain MGH78578, we measured whether cells of MGH78578 show strong activity of ethidium efflux or not. We observed much lower intracellular level of ethidium in MGH78578 compared with that in ATCC10031 under energized conditions (Fig. 1). After addition of $\mathrm{H}^{+}$conductor CCCP which dissipates an electrochemical potential of $\mathrm{H}^{+}$across cell membranes, intracellular level of ethidium increased and reached to the same level in the two strains. Thus, cells of MGH78578 showed strong energy-dependent ethidium efflux activity. These results suggest that high multidrug resistance in the MHG78578 is due to strong activities of multidrug efflux pumps.

Cloning of Genes Responsible for the Resistance We cloned DNA fragments that conferred resistance to antimicrobial gents such as norfloxacin, erythromycin, kanamycin, ethidium bromide, DAPI, and TPPCl from chromosomal DNA of K. pneumoniae MGH78578 using drug hypersensitive $E$. coli KAM32 as host. We obtained 43 candidate clones, 16 from plates containing ethidium bromide, 10 from norfloxacin plates, 9 from DAPI plates, 6 from erythromycin plates and 2 from kanamycin plates. All of the clones were 
Table 2. Growth Patterns of Candidate Clones Belonging to Each Group in the Presence of Drugs

\begin{tabular}{|c|c|c|c|c|c|c|c|c|c|c|}
\hline \multirow{2}{*}{ Group } & \multirow{2}{*}{ Number of clones } & \multicolumn{9}{|c|}{ Growth in the presence of } \\
\hline & & $\mathrm{EtBr}$ & NFLX & EM & KM & DR & DAPI & H33342 & R6G & $\mathrm{TPPCl}$ \\
\hline 1 & 4 & + & - & + & - & + & + & + & + & + \\
\hline 2 & 1 & + & - & + & + & + & - & + & + & - \\
\hline 3 & 2 & + & + & - & - & + & + & + & - & + \\
\hline 4 & 1 & + & + & - & - & - & + & + & - & + \\
\hline 5 & 4 & + & - & + & - & + & - & - & + & - \\
\hline 6 & 1 & - & - & \pm & + & + & - & + & \pm & - \\
\hline 7 & 5 & + & - & + & - & + & - & - & - & \pm \\
\hline 8 & 1 & + & + & - & - & - & - & - & + & - \\
\hline 9 & 1 & + & + & - & - & - & - & + & - & - \\
\hline 10 & 3 & + & - & - & - & - & + & - & - & + \\
\hline 11 & 2 & + & - & - & - & - & + & - & - & \pm \\
\hline 12 & 1 & + & + & - & - & - & - & - & - & - \\
\hline 13 & 1 & + & - & - & - & - & + & - & - & - \\
\hline 14 & 11 & - & + & - & - & - & + & - & - & - \\
\hline 15 & 1 & + & - & - & - & - & \pm & - & - & - \\
\hline 16 & 1 & + & - & - & - & - & - & - & \pm & - \\
\hline 17 & 3 & - & - & - & - & - & + & - & - & - \\
\hline
\end{tabular}

EtBr, ethidium bromide $(10 \mu \mathrm{g} / \mathrm{ml})$; NFLX, norfloxacin $(0.05 \mu \mathrm{g} / \mathrm{ml}) ; \mathrm{EM}$, erythromycin $(4 \mu \mathrm{g} / \mathrm{ml}) ; \mathrm{KM}$, kanamycin $(4 \mu \mathrm{g} / \mathrm{ml}) ; \mathrm{DR}, \mathrm{daunorubicine}(8 \mu \mathrm{g} / \mathrm{ml}) ; \mathrm{DAPI}, 4^{\prime}, 6-\mathrm{di}-$ amidino-2-phenylindole $(0.5 \mu \mathrm{g} / \mathrm{ml}) ; \mathrm{H} 33342$, Hoechst33342 $(0.5 \mu \mathrm{g} / \mathrm{ml}) ; \mathrm{R} 6 \mathrm{G}$, rhodamine $6 \mathrm{G}(10 \mu \mathrm{g} / \mathrm{ml})$; TPPCl, tetraphenylphosphonium chloride $(4 \mu \mathrm{g} / \mathrm{ml})$. + : cells grew, - : cells did not grow, \pm : intermediate

tested for their growth patterns in the presence of each one of the 9 antimicrobial agents listed in Table 2 . The growth pattern suggested that these 43 clones could be classified into 17 groups. Hybrid plasmids were prepared from the 43 clones, and their restriction patterns were compared after digestion with each one of the following 5 restriction enzymes, AflII, $E c o$ RV, MluI, StyI and PstI. It seemed that hybrid plasmids from each one of the groups possessed the same region of the chromosomal DNA, and that hybrid plasmids from different groups possessed different DNA regions. Thus, we classified the 43 hybrid plasmids into 17 groups depending on the growth patterns in the presence of antimicrobial agents and the restriction patterns (Table 2). Clones belonging to group 1 grew in the presence of 7 antimicrobial agents. Sequence of acrAB of $K$. pneumoniae $\mathrm{K} 23$ has been reported in DNA databases (DDBJ/EMBL/GenBank, accession number AJ318073). Judging from both the restriction patterns of our plasmid belonging to the group 1 and those predicted from sequence of the acr $A B$ region, it seemed that the plasmid of the group 1 carries the acr $A B$ region of $K$. pneumoniae. Clones belonging to group 2 and group 3 grew in the presence of 6 antimicrobial agents, followed by group 4 (5 antimicrobial agents), group 5 (4 antimicrobial agents), and group $6,7,8,9$ and 10 (at least 3 antimicrobial agents) (Table 2). Clones of other groups grew in the presence of ethidium bromide or DAPI although they did not grow in the presence of many other drugs. Both ethidium bromide and DAPI are known to be substrates for many multidrug efflux pumps, and no systems other than multidrug efflux pumps are known to cause resistance to these agents. Thus, we believe that most of the hybrid plasmids we obtained carry genes or operons for multidrug efflux pumps. On the other hand, we recently cloned a gene for regulatory protein that activated expression of gene for a multidrug efflux pumps from Serratia marcescens (unpublished results). Therefore some of the genes or operons we cloned may be for regulatory protein(s) for multidrug efflux genes.

The genome sequence of $K$. pneumoniae MGH78578 is available (http://genome.wustl.edu/projects/bacterial/kpneu moniae/). We deduced how many genes or operons for putative multidrug efflux pumps are present in the genome of $K$. pneumoniae MGH78578 based on deduced amino acid sequence similarity with sequence of known multidrug efflux pumps. We found at least 28 putative genes or operons for multidrug efflux pumps, 11 for RND-type pumps, 1 for MATE-type pump, 4 for SMR-type pumps, 10 for MF-type pumps and 2 for ABC-type pumps. We found another 15 possible genes for MF-type pumps and 6 for ABC-type pumps. Thus, total number of genes or operons for multidrug efflux pumps in this microorganism could be 28 to 59 . We also found 7 putative genes for outer membrane component for the RND-type pumps. Most of the 17 groups of genes or operons we cloned will represent major parts of the deduced genes or operons for multidrug efflux pumps in K. pneumoniae. Analyses of these 17 genes or operons and their products should reveal major parts of the multidrug efflux pumps in this microorganism. We partially determined DNA sequence of one plasmid from each group, and compared with genome sequence of $K$. pneumoniae (http://genome.wustl.edu/ projects/bacterial/kpneumoniae/). We found that the plasmid from group 2 carried a gene for SMR family multidrug efflux pump, plasmids from groups $4,9,10,11$ and 12 carried genes for MF family pumps, plasmids from groups 5, 7 and 8 in addition to group 1 carried genes for RND family pumps, plasmid from group 14 carried a gene for MATE family pump, and plasmids from group 13 and 15 carried genes for regulatory proteins. We were unable to identify genes in plasmids belonging to group 3, 6, 16 and 17 because of ambiguity of the genome database (http://genome.wustl.edu/projects/bacterial/kpneumoniae/). All of the multidrug efflux pumps in K. pneumoniae, genes for which have been cloned here, are hitherto uncharacterized pumps from biochemical point of view. We confirmed that plasmids belonging to different groups carried different portions of the genome DNA.

Our group has cloned many genes and operons responsible for multidrug resistance in $S$. marcescens using the same 
strategy. ${ }^{19)}$ We have been analyzing such genes and operons, and their products, multidrug efflux pumps. ${ }^{20}$ ) This type of approach is useful to investigate and understand major parts of multidrug resistance systems or multidrug efflux pumps in bacteria.

\section{REFERENCES}

1) Ishida T., Hashimoto T., Arita M., Ito I., Osawa M., Chest, 114, 1588 - 1593 (1998).

2) Hoban D. J., Biedenbach D. J., Mutnick A. H., Jones R. N., Diagn. Microbiol. Infect. Dis., 45, 279-285 (2003).

3) Jones M. E., Karlowsky J. A., Draghi D. C., Thornsberry C., Sahm D. F., Bradley J. S., Eur. J. Clin. Microbiol. Infect. Dis., 23, 445-455 (2004).

4) Pedersen G., Schonheyder H. C., Sorensen H. T., Scand. J. Infect. Dis., 29, 601-606 (1997).

5) De Champs C., Rich C., Chandezon P., Chanal C., Sirot D., Forestier C., Eur. J. Clin. Microbiol. Infect. Dis., 23, 456-462 (2004).

6) Hasdemir U. O., Chevalier J., Nordmann P., Pages J. M., J. Clin. Microbiol., 42, 2701-2706 (2004).

7) Pagani L., Perilli M., Migliavacca R., Luzzaro F., Amicosante G., Eur. J. Clin. Microbiol. Infect. Dis., 19, 765-772 (2000).
8) Sekowska A., Janicka G., Klyszejko C., Wojda M., Wroblewski M., Szymankiewicz M., Med. Sci. Monit., 8, BR100-104 (2002).

9) Li X. Z., Nikaido H., Drugs, 64, 159-204 (2004).

10) Schumacher H., Scheibel J., Moller J. K., J. Antimicrob. Chemother. 46, 215-221 (2000).

11) Chen F. J., Lauderdale T. L., Ho M., Lo H. J., Microb. Drug Resist., 9 265-271 (2003).

12) Deguchi T., Fukuoka A., Yasuda M., Nakano M., Ozeki S., Kanematsu E., Nishino Y., Ishihara S., Ban Y., Kawada Y., Antimicrob. Agents Chemother, 41, 699-701 (1997).

13) Fendukly F., Karlsson I., Hanson H. S., Kronvall G., Dornbusch K., APMIS, 111, 857-866 (2003).

14) Mazzariol A., Zuliani J., Cornaglia G., Rossolini G. M., Fontana R., Antimicrob. Agents Chemother, 46, 3984-3986 (2002).

15) Chen J., Morita Y., Huda M. N., Kuroda T., Mizushima T., Tsuchiya T., J. Bacteriol., 184, 572-576 (2002).

16) Japan Society of Chemotherapy, Chemother. (Tokyo), 38, 103-105 (1990).

17) Tanaka S., Lerner S. A., Lin E. C., J. Bacteriol., 93, 642 -648 (1967).

18) Berns K. I., Thomas C. A., Jr., J. Mol. Biol., 11, 117-120 (1965).

19) Chen J., Lee E.W., Kuroda T., Mizushima T., Tsuchiya T., Biol. Pharm. Bull., 26, 391-393 (2003).

20) Chen J., Kuroda T., Huda M. N., Mizushima T., Tsuchiya T., J. Antimicrob. Chemother, 52, 176-179 (2003). 